\title{
Antibiotic resistance, biofilm formation, and biofilm-associated genes among Stenotrophomonas maltophilia clinical isolates
}

\author{
Narjess Bostanghadiri ${ }^{1}$, Abdollah Ardebili ${ }^{2,3}$, Zohreh Ghalavand ${ }^{4}$, Samane Teymouri ${ }^{1}$, Mahsa Mirzarazi ${ }^{5}$, \\ Mehdi Goudarzi ${ }^{4}$, Ehsan Ghasemi ${ }^{6}$ and Ali Hashemi ${ }^{4 *}$ (D)
}

\begin{abstract}
Objective: The purpose of the present study was to investigate the antimicrobial susceptibility pattern, biofilm production, and the presence of biofilm genes among the S. maltophilia clinical isolates. A total of 85 clinical isolates of S. maltophilia were collected from patients referred to several hospitals. Susceptibility to antibiotics was investigated by disc diffusion method according to the guidelines of the Clinical and Laboratory Standards Institute (CLSI). By the crystal violet staining method, the capability of biofilm formation was examined. The genes associated with biofilm production were investigated by the PCR-sequencing techniques.

Results: All isolates were resistant to doripenem, imipenem, and meropenem. Minocycline, trimethoprim/sulfamethoxazole and levofloxacin exhibited the highest susceptibility of 100\%, 97.65\%, and $95.29 \%$, respectively. The results of crystal violet staining assay showed that all isolates (100\%) form biofilm. Moreover, 24 (28.23\%), 32 (37.65\%), and 29 (34.12\%) of isolates were categorized as weak, moderate, and strong biofilm producers, respectively. Biofilm genes including rpfF, spgM and $r m$ IA had an overall prevalence of $89.41 \%$ (76/85), 100\% (85/85) and $84.71 \%$ (72/85), respectively. Rational prescribing of antibiotics and implementation of infection control protocols are necessary to prevent further infection and development of antimicrobial resistance. Combination strategies based on the appropriate antibiotics along with anti-biofilm agents can also be selected to eliminate biofilm-associated infections.
\end{abstract}

Keywords: Stenotrophomonas maltophilia, Antibiotic resistance, Biofilm, Biofilm formation genes

\section{Introduction}

Stenotrophomonas maltophilia, previously known as Pseudomonas maltophilia or Xanthomonas maltophilia, has become nowadays a major opportunistic pathogen in hospitalized or immunocompromised patients worldwide [1]. This organism is the most prevalent nonfermenting Gram-negative bacilli in clinical laboratories

*Correspondence: ali.hashemi@sbmu.ac.ir; Hashemi1388@yahoo.com

${ }^{4}$ Department of Microbiology, School of Medicine, Shahid Beheshti

University of Medical Sciences, Tehran, Iran

Full list of author information is available at the end of the article after P. aeruginosa and Acinetobacter baumannii [2]. In addition, it is known to causes severe infections such as acute exacerbations of chronic obstructive pulmonary disease (COPD), pneumonia, bacteremia, sepsis, bone, and joint infections, eye infections, endocarditis, and meningitis [3, 4]. S. maltophilia isolates show resistance to a variety of antibacterial agents, with various types of antimicrobial resistance mechanisms [5-7], leading to a great challenge for physicians and clinical microbiologists to manage related infections $[8,9]$.

A prominent feature of $S$. maltophilia is its capability to adhere to abiotic surfaces, host tissues and biofilm

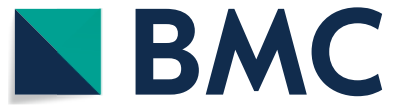

(c) The Author(s) 2021. This article is licensed under a Creative Commons Attribution 4.0 International License, which permits use, sharing, adaptation, distribution and reproduction in any medium or format, as long as you give appropriate credit to the original author(s) and the source, provide a link to the Creative Commons licence, and indicate if changes were made. The images or other third party material in this article are included in the article's Creative Commons licence, unless indicated otherwise in a credit line to the material. If material is not included in the article's Creative Commons licence and your intended use is not permitted by statutory regulation or exceeds the permitted use, you will need to obtain permission directly from the copyright holder. To view a copy of this licence, visit http://creativecommons.org/licenses/by/4.0/. The Creative Commons Public Domain Dedication waiver (http://creativecommons.org/publicdomain/zero/1.0/) applies to the data made available in this article, unless otherwise stated in a credit line to the data. 
formation [10, 11]. S. maltophilia has been identified on the surfaces of biomaterials used in prosthetic devices, intravenous cannula, dental unit waterlines and nebulizers [12-14]. The biofilm-forming capacity of $S$. maltophilia has increasingly been accepted as an important virulence factor and is thought to play a significant role in the persistence of S. maltophilia infections in hospital settings [10, 15-19] The molecular mechanisms of biofilm formation in S. maltophilia is poorly investigated $[18,19]$. Several genes are associated with biofilm-formation. The spgM gene encodes a bifunctional enzyme with both phosphoglucomutase and phosphomannomutase activities that is involved in LPS biosynthesis, playing an important role in biofilm formation [18, 20]. Mutation in spgM gene, may cause fewer LPS production and shorter $\mathrm{O}$ polysaccharide chains [21]. The rmlA gene encodes glucose-1-phosphate thymidyltransferas that is involved in LPS/EPS-coupled biosynthetic pathway It is reported that mutations in $r m l A$ and $r p f F$ genes resulted in reduced biofilm formation in S. maltophilia $[4,19]$. The $r p f F$ gene, encoding the DSF (diffusible signal factor) synthase regulates the virulence expression, such as motility, extracellular proteases, LPS, and biofilm production. RpfF protein has some amino acid sequences similar to enoyl coenzyme A hydratases [19].

Considering the potential of biofilm in increasing antimicrobial resistance and subsequently, the increased rates of chronic infections caused by $S$. maltophilia, identification of the isolates with such factor will be benefit to better understand the pathogenesis of the organism. The aim of this survey was to investigate the pattern of antibiotic susceptibility, the ability of biofilm production, and the presence of biofilm-related genes in clinical S. maltophilia isolates.

\section{Main text \\ Methods \\ Bacterial isolates and species identification}

S. maltophilia isolates included in this study were originated from different clinical samples of patients admitted at selected hospitals in Tehran, Iran from January 2018 to January 2019. All of the isolates were identified by standard microbiological and biochemical methods, including catalase and oxidase tests, reactions in media, such as triple sugar iron agar, deoxyribonuclease test agar, and SIM (Merck company, Germany). S. maltophilia isolates were then confirmed by the PCR amplification of the 16S rRNA gene and sequencing (Table 1). All isolates were stored in Luria-Bertani (LB) liquid medium (Merck company-Germany) containing $15 \%$ glycerol at $-80{ }^{\circ} \mathrm{C}$. Escherichia coli ATCC 25,922 and S. maltophilia ATCC 13,637 were used as the quality control strains.
Table 1 Oligonucleotide primers used in this study

\begin{tabular}{llll}
\hline Genes & Sequences $\left(5^{\prime} \rightarrow 3^{\prime}\right)$ & Target & References \\
\hline 16rrRNA-F & AGTTCGCATCGTTAGGG & 16 s RNA & {$[2]$} \\
16srRNA-R & ACGGCAGCACAGAAGAGC & & \\
spgM-F & ATACCGGGGTGCGTTGAC & spgM & {$[18]$} \\
spgM- $R$ & CATCTGCATGTGGATCTCGT & & \\
$r p f F-F$ & CACGACAGTACAGGGGACC & rpfF & {$[18]$} \\
$r p f F-R$ & GGCAGGAATGCGTTGG & & \\
$r m \mid A-F$ & CGGAAAAGCAGAACATCG & rmlA & {$[3]$} \\
$r m \mid A-R$ & GCAACTTGGTTCAATCACTT & & \\
\hline
\end{tabular}

\section{Antimicrobial susceptibility testing}

The antibiotic sensitivity pattern of $S$. maltophilia isolates was evaluated by the Kirby-Bauer disc diffusion method as described by the Clinical and Laboratory Standards Institute (CLSI) [22]. Antibiotic discs used for susceptibility testing were levofloxacin $(5 \mu \mathrm{g})$, minocycline $(30 \mu \mathrm{g})$, imipenem $(10 \mu \mathrm{g})$, meropenem $(10 \mu \mathrm{g})$, doripenem $(10 \mu \mathrm{g})$, sulfamethoxazole/trimethoprim (SMX/ TMP) $(1.25 / 23.75 \mu \mathrm{g})$, tetracycline $(30 \mu \mathrm{g})$, and ceftazidime $(30 \mu \mathrm{g})$ (MAST Diagnostics, Merseyside, UK). Control strains of E. coli ATCC 25922 and E. coli ATCC 35218 were used for susceptibility testing.

\section{DNA preparation}

S. maltophilia isolates were cultivated on Columbia agar medium (bioMérieux Italia S.p.A-Italy) supplemented with $5 \%$ sheep blood and incubated at $37^{\circ} \mathrm{C}$ for $24 \mathrm{~h}$. The DNA samples were extracted from the grown colonies of each isolate with high pure PCR Template Preparation Kit (Roche company-Germany). The total DNA concentration was evaluated by Nanodrop (WPA Biowave II Nanospectrophotometer-USA).

\section{PCR-sequencing techniques}

The presence of biofilm-encoding genes, including $r p f F$, spgM, and $r m l A$ was investigated in S. maltophilia isolates by PCR technique using the specific primers (Table 1 ). PCRs were performed on a thermal cycler (Eppendorf, Master Cycler Gradient- Germany) in 25- $\mu$ l reaction volumes with $1 \mu \mathrm{l}(20 \mathrm{ng})$ of DNA template, $1 \times$ PCR buffer, $12.5 \mu \mathrm{l}$ of $2 \times$ Master Mix (SinaClon-Iran), $3 \mathrm{mmol} / \mathrm{L}$ $\mathrm{MgCl}_{2}, 0.4 \mathrm{mmol} / \mathrm{L} \mathrm{dNTPs}, 9.5 \mu \mathrm{l}$ of sterile distilled water, $1 \mu \mathrm{l}$ of $10 \mathrm{pmol}$ of each primer, and $0.08 \mathrm{IU}$ of Taq DNA polymerase. PCR conditions were under the following: denaturation at $95{ }^{\circ} \mathrm{C}$ for $10 \mathrm{~min}$, and then 36 cycles at $94{ }^{\circ} \mathrm{C}$ for $60 \mathrm{~s}$, annealing at $52-60{ }^{\circ} \mathrm{C}$, depending to the primers for each gene, for $60 \mathrm{~s}$, and extension at $72{ }^{\circ} \mathrm{C}$ for $60 \mathrm{~s}$, followed by a final extension at $72{ }^{\circ} \mathrm{C}$ for $5 \mathrm{~min}$. PCR 
products were electrophoresed by $1.2-1.5 \%$ agarose gel, visualized by DNA Safe staining, and then photographed under UV light.

The amplicons were purified using a PCR purification Kit (BioFact Co., South Korea), and then sequenced by an ABI PRISM 3700 sequencer (Applied Biosystems Inc., USA). The nucleotide sequences were analyzed using FinchTV software and comparisons were made using the NCBI BLAST program (http://www.ncbi.nlm.nih.gov/ BLAST/).

\section{Biofilm formation assay}

Biofilm formation by S. maltophilia was evaluated using crystal violet staining method as previously described by Stepanović et al. [23]. All experiments were run in triplicate. An overnight culture of isolates was adjusted to the turbidity of a $1.0 \mathrm{McF}$ arland standard. Suspensions were diluted at a ratio of 1:100 in $200 \mathrm{ml}$ tryptic soy broth (TSB) (Merck, Darmstadt- Germany) containing 1\% glucose and, were dispensed to the sterile flat-bottomed 96- well polystyrene microplates (JET Biofil, Guangzhou, China). After $24 \mathrm{~h}$ of incubation at $37{ }^{\circ} \mathrm{C}$, microplates were washed three times with sterile phosphate-buffered saline (PBS, $\mathrm{pH} 7.3$ ). Adherent biofilms were fixed for $1 \mathrm{~h}$ at $60{ }^{\circ} \mathrm{C}$, stained by $200 \mu \mathrm{l}$ Hucker modified crystal violet (Sigma Chemical Company- USA) for $5 \mathrm{~min}$ at room temperature and then rinsed with water and allowed to dry. Biofilm samples were destained with $200 \mathrm{ml} 33 \%$ glacial acetic acid for $15 \mathrm{~min}$. The optical density (OD) was measured at $492 \mathrm{~nm}$ using a microtiter plate reader (BioTek, Bad Friedrichshall, Germany). A cut-off value (ODc) was established. It is defined as three standard deviations (SD) above the mean OD of the negative control: $\mathrm{ODc}=$ average $\mathrm{OD}$ of negative control $+(3 \times \mathrm{SD}$ of negative control). The isolates were categorized into four groups according to the following criteria: nonbiofilm producer $(\mathrm{OD}<\mathrm{ODc})$, weak-biofilm producer $\left(\mathrm{ODc}<\mathrm{OD}<\_2 \times \mathrm{ODc}\right)$, moderate-biofilm producer $(2 \times \mathrm{ODc}<\mathrm{OD}<4 \times \mathrm{ODc})$, and strong-biofilm producer $(4 \times \mathrm{ODc}<\mathrm{OD})$.

\section{Statistical analysis}

The statistical analysis of data was performed with statistical software SPSS, 20.0 (SPSS Inc., Chicago, IL, USA). Chi-squared test was used to determine the association between categorical variables. A $p$-value $\leq 0.05$ was considered statistically significant.

\section{Results}

\section{Patients and bacterial isolates}

During one-year period, 85 S. maltophilia isolates were gathered from several health centers in Tehran, Iran. Among them, 49 isolates were from males and 36 isolates from females (male: female ratio $=1.36$ ). Most of the $S$. maltophilia (90.03\%) were isolated from the blood, while the rest $(9.97 \%)$ were from the cough swabs. The range of patients' age was from 2 months to 85 years.

\section{Antimicrobial susceptibility}

The results of susceptibility testing on planktonic cells showed that approximately 100\%, 96\%, 96\%, 36.58\%, $2.35 \%$ of the S. maltophilia isolates were resistant to imipenem, doripenem, meropenem, ceftazidime and SMX/TMP-, respectively. Levofloxacin and minocycline (95.29\% and $100 \%$ susceptibile, respectively) exhibited the highest activity against $S$. maltophilia, with a rate of (Table 2).

\section{Biofilm formation}

In this study, the biofilm forming ability was assessed on polystyrene using the microtiter plate method. Biofilm phenotypes accounted for $100 \%$, being distributed as follow: 24 isolates $(28.23 \%)$ produced weak biofilm, 32 isolates $(37.65 \%)$ produced moderate biofilm, and 29 isolates (34.12\%) produced strong biofilm.

\section{Biofilm-encoding genes}

The frequency of biofilm-related genes among the $S$. maltophilia isolates was generally as high as $89.41 \%$, $100 \%$, and $84.71 \%$ for rmlA, spgM and rpfF genes, respectively (Fig. 1). Among them, 63 isolates carried all three genes studied. S. maltophilia isolates with $s p g M+/ r p f F+/ r m l A+$ genotype showed strong or moderate biofilm-producer phenotype.

\section{Discussion}

S. maltophilia is increasingly identified as a cause of nosocomial infections, especially among immunosuppressed patients [24]. Treatment of infections caused by this pathogen is a problem for clinicians because of

Table 2 Antibiotic susceptibility of S. maltophilia clinical isolates $(n=85)$

\begin{tabular}{llll}
\hline Antimicrobial agents & \multicolumn{2}{l}{$\begin{array}{l}\text { Antimicrobial susceptibility pattern, } \mathrm{n} \\
(\%)\end{array}$} & \multicolumn{2}{l}{ Susceptible } & Intermediate & Resistant \\
\cline { 2 - 4 } & - & - & $85(100 \%)$ \\
\hline Imipenem & - & - & $85(100 \%)$ \\
Meropenem & - & - & $85(100 \%)$ \\
Doripenem & $24(28.24 \%)$ & - & $61(75.72 \%)$ \\
Ceftazidime & $85(100 \%)$ & - & - \\
Minocycline & $81(95.29 \%)$ & - & $4(4.71 \%)$ \\
Levofloxacin & $83(97.65 \%)$ & - & $2(2.35 \%)$ \\
Sulfamethoxazole/trimetho- & & & \\
prim & & & \\
\hline
\end{tabular}




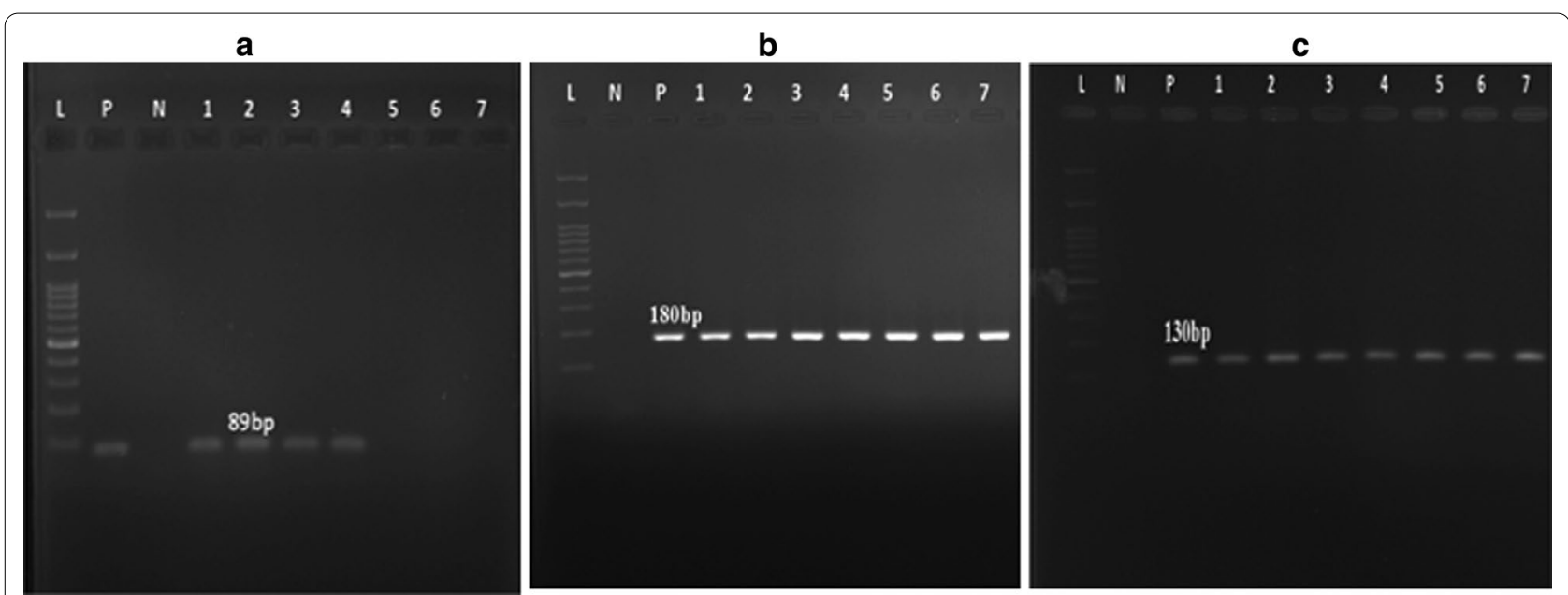

Fig. 1 The amplification of biofilm-encoding genes in S. maltophilia isolates. L: 100 bp DNA ladder, P: positive control, N: negative control, Lanes 1 to 7: PCR products of the corresponding genes: $\mathbf{a}$; $r$ rmIA gene, $\mathbf{b}$; $r p f f$ gene, $\mathbf{c}$; spgM gene

its resistance to a broad array of antimicrobial drugs [25]. In the present study, all isolates were resistant to carbapenems $(p \leq 0.001)$. Similarly, a previous study showed that resistance rates to imipenem and meropenem in S. maltophilia were $100 \%$ and $92.4 \%$, respectively [26]. Moreover, our results showed a susceptibility rate of $28.24 \%$ to ceftazidime. A study by Farrell et al. showed that susceptibility of S. maltophilia against ceftazidime was $32.51 \%$ in Latin America, North America, Asian-Pacific, and Europe [26]. In contrast, Jamali et al. reported the susceptibility rate of $82 \%$ against this drug [27]. In our study, $100 \%$ and $95.29 \%$ of S. maltophilia were susceptible to minocycline and levofloxacin, respectively. Duan et al. showed also the susceptibility rates of $100 \%$ and $95.7 \%$ to minocycline and levofloxacin, respectively [28]. These findings indicate that such antibiotics serve as effective agents for treatment of $S$. maltophilia infections. On the other hand, the most effective antimicrobial agent used to treat $S$. maltophilia infections is SMX/TMP [29]. In a study by Jamali et al., $5 \%$ of isolates were resistant to SMX/TMP [30]. The susceptibility rates were reported as high as $95 \%$ in several studies conducted in most regions, including Latin America, North America, Europe [3032]. In our study, $97.65 \%$ of isolates were found to be susceptible to SMX/TMP, indicating this antibiotic has increasingly become the last resort drug for the treatment of multi-resistant S. maltophilia infections. However, the highest rates of resistance have been reported in isolates obtained from patients in Asian countries, such as Malaysia, Korea, and Taiwan [33]. The present study generally reveals a low frequency of antibiotic resistance among the $S$. maltophilia. However, monitoring of the antibiotic resistance trends is nesserary either geographically or over time.

All S. maltophilia isolates tested in this study were able to produce biofilms. In a study by Flores-Trevino et al., isolates were categorized as weak- $(47.9 \%)$, moderate- (38.7\%), or strong- (13.4\%) biofilm producers [34]. In contrast, Gallo et al. showed that isolates were biofilm producers as weak (3\%), moderate $(45 \%)$, or strong $(48 \%)$ [35]. From 2016 to 2017 in Iran, 47.9, 38.7, and 13.4\% of out of 164 S. maltophilia clinical isolates were weak-, moderate-, and strong-biofilm producers, respectively [36].

Biofilms have been recognized to be involved in many chronic and intractable infections [13,37]. The results of this study showed biofilm formation significantly correlated with ceftazidime and SMX/TMP resistance. Similarly, biofilm formation has been shown associated with resistance to different antibiotics, including ceftazidime, piperacillin/tazobactam, cefepime, ticacillin/clavulanic acid, aztreonam, and gentamicin [38]. more understanding of biofilm dynamics can lead to development of a effective treatment, and control, strategies for eradication of infections, improving patient care [39].

In the present study, we investigated the relationship between biofilm formation and the presence of its related genes $r p f F$, spgM, and $r m l A$. Sixty-three isolates of $S$. maltophilia strains had all genes studied, while only 81 strains carried the spgM. Overall, our results revealed that the presence of the $s p g M$ significantly promoted biofilm formation, in accordance to those obtained by Pompilio et al. [40]. In a study by Zhongliang Duan et al. the rates of spgM, rmlA, and rpfF biofilm genes were $100 \%, 83.7 \%$, and $45.2 \%$, respectively 
[17]. Zhuo et al. indicated that biofilm formation was considerably associated with the presence of rpfF and $s p g M$ genes [18]. Moreover, the presence of either rpfF or spgM was significantly correlated to biofilm production, although the strongest biofilm was formed when both genes were present [15]. The presence of $s p g M$, $r p f F$, and $r m l A$ genes improved significantly the biofilm production in our isolates.

In conclusion, although the rate of resistance to multiple antibiotics among our S. maltophilia isolates was relatively low, cautious antimicrobial use and high standards of infection prevention and control are needed to prevent further development of resistant isolates. Additionally, combination strategies based on the proper antibiotics with anti-biofilm agents can be used to improve the treatment of biofilm-associated infections.

\section{Limitations}

A limitation of this study may be the lack of evaluation of expression levels of biofilm-associated genes by quantitative real-time PCR, an approach that may help to assess the role of each corresponding gene in biofilm production.

\section{Abbreviations}

CLSI: Clinical and laboratory standards institute; COPD: Chronic obstructive pulmonary disease; EPS: Extracellular matrix polysaccharides; PGM: Phosphoglucomutase; TSB: Tryptic soy broth; OD: Optical density; PCR: Polymerase chain reaction.

\section{Acknowledgements}

This study was financially supported by the Research Department of the School of Medicine, Shahid Beheshti University of Medical Sciences (Grant No. 19223).

\section{Authors' contributions}

NBG, AH, AA, ST, AR, MM, MG, EG and ZG involved in the management of the project and writing up the paper. $\mathrm{NBG}, \mathrm{AH}$ and $\mathrm{ZG}$ involved in collecting of samples and performing of the study. NBG and AH involved in analysis of results. All authors read and approved the final manuscript.

\section{Funding}

This study was financially supported by the Research Department of the School of Medicine, Shahid Beheshti University of Medical Sciences (Grant No.21153).

\section{Availability of data and materials}

The datasets generated and analyzed during this reasearch were included in the main document of this manuscript.

\section{Declarations}

\section{Ethics approval and consent to participate}

The clinical samples collected were in line with the patients' diagnostic stages and no additional samples were taken. This research was approved by the Ethics Committee of Shahid Beheshti University of Medical Sciences with the ethical code number IR.SBMU.MSP.REC.1399.28. The satisfaction of each patient was done before their cooperation. First, the research was explained verbally for each patient, afterward the informed consent form was signed by participants.

\section{Consent for publication}

Not applicable.

\section{Competing interests}

There are no conflicts of interest.

\section{Author details}

${ }^{1}$ Department of Microbiology, School of Medicine, Iran University of Medical Sciences, Tehran, Iran. ${ }^{2}$ Laboratory Sciences Research Center, Golestan University of Medical Sciences, Gorgan, Iran. ${ }^{3}$ Department of Microbiology, Faculty of Medicine, Golestan University of Medical Sciences, Gorgan, Iran.

${ }^{4}$ Department of Microbiology, School of Medicine, Shahid Beheshti University of Medical Sciences, Tehran, Iran. ${ }^{5}$ Student Research Committee, Department of Medical Biotechnology, School of Advanced Technologies in Medicine, Shahid Beheshti University of Medical Sciences, Tehran, Iran. ${ }^{6}$ Abadan School of Medical Sciences, Abadan, Iran.

Received: 5 November 2020 Accepted: 13 April 2021

Published online: 20 April 2021

\section{References}

1. Moriceau C, Eveillard M, Lemarié C, Chenouard R, Pailhoriès H, Kempf M. Stenotrophomonas maltophilia susceptibility to ceftazidime-avibactam combination versus ceftazidime alone. Med Mal Infect. 2020;50:305-7.

2. Wang A, Wang Q, Kudinha T, Xiao S, Zhuo C. Effects of fluoroquinolones and azithromycin on biofilm formation of Stenotrophomonas maltophilia. Sci Rep. 2016:6:29701.

3. Bostanghadiri N, Ghalavand Z, Fallah F, Yadegar A, Tarashi S, Pournajaf A, et al. Characterization of phenotypic and genotypic diversity of Stenotrophomonas maltophilia strains isolated from selected hospitals in Iran. Front Microbiol. 2019;10:1191.

4. Pompilio A, Savini V, Fiscarelli E, Gherardi G, Di Bonaventura G. Clonal diversity, biofilm formation, and antimicrobial resistance among Stenotrophomonas maltophilia strains from cystic fibrosis and non-cystic fibrosis patients. Antibiotics. 2020;9(1):15.

5. Rahmati Roodsari M, Fallah F, Taherpour A, Hakemi Vala M, Hashemi A. Carbapenem-resistant bacteria and laboratory detection methods. Archiv Pediatric Infect Dis. 2014;2(1):188-91.

6. Pompilio A, Crocetta V, De Nicola S, Verginelli F, Fiscarelli E, Di Bonaventura G. Cooperative pathogenicity in cystic fibrosis: Stenotrophomonas maltophilia modulates Pseudomonas aeruginosa virulence in mixed biofilm. Front Microbiol. 2015;6:951.

7. Cruz-Córdova A, Mancilla-Rojano J, Luna-Pineda VM, Escalona-Venegas G, Cazares-Dominguez V, Ormsby C, et al. Molecular epidemiology, antibiotic resistance, and virulence traits of Stenotrophomonas maltophilia strains associated with an outbreak in a mexican tertiary care hospital. Front Cell Infect Microbiol. 2020;10:50.

8. Mojica MF, Rutter JD, Taracila M, Abriata LA, Fouts DE, Papp-Wallace KM, et al. Population structure, molecular epidemiology, and $\beta$-lactamase diversity among Stenotrophomonas maltophilia isolates in the United States. MBio. 2019:10(4):e00405-e419.

9. Adegoke AA, Stenström TA, Okoh Al. Stenotrophomonas maltophilia as an emerging ubiquitous pathogen: looking beyond contemporary antibiotic therapy. Front Microbiol. 2017;8:2276.

10. Pompilio A, Crocetta V, Confalone P, Nicoletti M, Petrucca A, Guarnieri S, et al. Adhesion to and biofilm formation on IB3-1 bronchial cells by Stenotrophomonas maltophilia isolates from cystic fibrosis patients. BMC Microbiol. 2010;10(1):102.

11. Ghasemi E, Ghalavand Z, Goudarzi H, Yeganeh F, Hashemi A, Dabiri H, et al. Phenotypic and genotypic investigation of biofilm formation in clinical and environmental isolates of Acinetobacter baumannii. Archiv Clin Infect Dis. 2018;13(4):12914.

12. Irie Y, Roberts AE, Kragh KN, Gordon VD, Hutchison J, Allen RJ, et al. The Pseudomonas aeruginosa PSL polysaccharide is a social but noncheatable trait in biofilms. MBio. 2017;8(3):e00374.

13. Brooke JS. Stenotrophomonas maltophilia: an emerging global opportunistic pathogen. Clin Microbiol Rev. 2012;25(1):2-41. 
14. Høiby N, Bjarnsholt T, Givskov M, Molin S, Ciofu O. Antibiotic resistance of bacterial biofilms. Int J Antimicrob Agents. 2010;35(4):322-32.

15. Madi H, Lukić J, Vasiljević Z, Biočanin M, Kojić M, Jovčić B, et al. Genotypic and phenotypic characterization of Stenotrophomonas maltophilia strains from a pediatric tertiary care hospital in Serbia. PLoS ONE. 2016;11(10):e0165660.

16. Liu W, Tian X-Q, Wei J-W, Ding L-L, Qian W, Liu Z, et al. BsmR degrades c-di-GMP to modulate biofilm formation of nosocomial pathogen Stenotrophomonas maltophilia. Sci Rep. 2017:7(1):1-15.

17. Duan Z, Qin J, Li C, Ying C. Clinical and molecular epidemiology of Stenotrophomonas maltophilia in pediatric patients from a Chinese teaching hospital. Front Cell Infect Microbiol. 2020;10:411.

18. Zhuo C, Zhao Q-y, Xiao S-n. The impact of spgM, rpfF, rmlA gene distribution on biofilm formation in Stenotrophomonas maltophilia. PLOS ONE. 2014;9(10):108409.

19. Fouhy Y, Scanlon K, Schouest K, Spillane C, Crossman L, Avison MB, et al. Diffusible signal factor-dependent cell-cell signaling and virulence in the nosocomial pathogen Stenotrophomonas maltophilia. J Bacteriol. 2007;189(13):4964-8.

20. Huang T-P, Somers EB, Wong ACL. Differential biofilm formation and motility associated with lipopolysaccharide/exopolysaccharide-coupled biosynthetic genes in Stenotrophomonas maltophilia. J Bacteriol. 2006;188(8):3116-20.

21. McKay GA, Woods DE, MacDonald KL, Poole K. Role of phosphoglucomutase of Stenotrophomonas maltophilia in lipopolysaccharide biosynthesis, virulence, and antibiotic resistance. Infect Immun. 2003;71(6):3068-75

22. Wayne P. Clinical and laboratory standards institute (CLSI). Performance standards for antimicrobial susceptibility testing Twenty-second informational supplement M100-S21 United States, Wayne. 2012.

23. Stepanović S, Vuković D, Hola V, Bonaventura GD, Djukić S, Cirković I, et al. Quantification of biofilm in microtiter plates: overview of testing conditions and practical recommendations for assessment of biofilm production by staphylococci. APMIS. 2007;115(8):891-9.

24. Huang C-R, Chen S-F, Tsai N-W, Chang C-C, Lu C-H, Chuang Y-C, et al. Clinical characteristics of Stenotrophomonas maltophilia meningitis in adults: a high incidence in patients with a postneurosurgical state, long hospital staying and antibiotic use. Clin Neurol Neurosurg. 2013;115(9):1709-15.

25. Steinmann J, Mamat U, Abda EM, Kirchhoff L, Streit WR, Schaible UE, et al. Analysis of phylogenetic variation of Stenotrophomonas maltophilia reveals human-specific branches. Front Microbiol. 2018;9:806.

26. Farrell DJ, Sader HS, Jones RN. Antimicrobial susceptibilities of a worldwide collection of Stenotrophomonas maltophilia isolates tested against tigecycline and agents commonly used for S. maltophilia infections. Antimicrobial Agents Chemotherapy. 2010;54(6):2735-7.

27. Jamali F, Boroumand MA, Yazdani F, Anvari MS, Pourgholi L, Mahfouzi S, et al. Minimal inhibitory concentration of ceftazidime and Co-trimoxazole for Stenotrophomonas maltophilia using E-test. J Global Infect Dis. 2011;3(3):254

28. Duan Z, Qin J, Liu Y, Li C, Ying C. Molecular epidemiology and risk factors of Stenotrophomonas maltophilia infections in a Chinese teaching hospital. BMC Microbiol. 2020;20(1):1-9.
29. Herrera Heredia SA, Pezina Cantú C, Garza González E, Bocanegra Ibarias P, Mendoza Olazarán SS, Morfín Otero R, et al. Risk factors and molecular mechanisms associated with trimethoprim-sulfamethoxazole resistance in Stenotrophomonas maltophilia in Mexico. J Med Microbiol. 2017:66(8):1102-9.

30. Gales AC, Seifert H, Gur D, Castanheira M, Jones RN, Sader HS, editors. Antimicrobial susceptibility of Acinetobacter calcoaceticus-Acinetobacter baumannii complex and Stenotrophomonas maltophilia clinical isolates: results from the SENTRY antimicrobial surveillance program (1997-2016). Open forum infectious diseases; 2019: Oxford University Press US.

31. Elufisan TO, Rodriguez-Luna IC, Oyedara OO, Sanchez-Varela A, García VB, Oluyide BO, et al. Antimicrobial susceptibility pattern of Stenotrophomonas species isolated from Mexico. Afr Health Sci. 2020;20(1):168-81.

32. Brooke JS. New strategies against Stenotrophomonas maltophilia: a serious worldwide intrinsically drug-resistant opportunistic pathogen. Taylor Francis. 2014;12:1-4.

33. Rhee J-Y, Song J-H, Ko KS. Current situation of antimicrobial resistance and genetic differences in Stenotrophomonas maltophilia complex isolates by multilocus variable number of tandem repeat analysis. Infect Chemotherapy. 2016;48(4):285-93.

34. Flores-Treviño S, Gutierrez-Ferman JL, Morfín-Otero R, Rodríguez-Noriega E, Estrada-Rivadeneyra D, Rivas-Morales C, et al. Stenotrophomonas maltophilia in Mexico: antimicrobial resistance, biofilm formation and clonal diversity. J Med Microbiol. 2014;63(11):1524-30.

35. Gallo SW, Figueiredo TP, Bessa MC, Pagnussatti VE, Ferreira CA, Oliveira SD Isolation and characterization of Stenotrophomonas maltophilia isolates from a brazilian hospital. Microb Drug Resist. 2016;22(8):688-95.

36. Bostanghadiri N, Ghalavand Z, Fallah F, Yadegar A, Ardebili A, Tarashi S, et al. Characterization of phenotypic and genotypic diversity of Stenotrophomonas maltophilia strains isolated from selected hospitals in Iran. Front Microbiol. 2019:10:1191

37. Vestby LK, Grønseth T, Simm R, Nesse LL. Bacterial biofilm and its role in the pathogenesis of disease. Antibiotics. 2020;9(2):59.

38. Liaw S-J, Lee Y-L, Hsueh P-R. Multidrug resistance in clinical isolates of Stenotrophomonas maltophilia: roles of integrons, efflux pumps, phosphoglucomutase (SpgM), and melanin and biofilm formation. Int J Antimicrob Agents. 2010;35(2):126-30.

39. Flores-Treviño S, Bocanegra-Ibarias P, Camacho-Ortiz A, Morfín-Otero R, Salazar-Sesatty HA, Garza-González E. Stenotrophomonas maltophilia biofilm: its role in infectious diseases. Expert Rev Anti Infect Ther. 2019;17(11):877-93

40. Pompilio A, Piccolomini R, Picciani C, D'Antonio D, Savini V, Di Bonaventura G. Factors associated with adherence to and biofilm formation on polystyrene by Stenotrophomonas maltophilia: the role of cell surface hydrophobicity and motility. FEMS Microbiol Lett. 2008;287(1):41-7.

\section{Publisher's Note}

Springer Nature remains neutral with regard to jurisdictional claims in published maps and institutional affiliations.

Ready to submit your research? Choose BMC and benefit from

- fast, convenient online submission

- thorough peer review by experienced researchers in your field

- rapid publication on acceptance

- support for research data, including large and complex data types

- gold Open Access which fosters wider collaboration and increased citations

- maximum visibility for your research: over 100M website views per year

At BMC, research is always in progress.

Learn more biomedcentral.com/submissions 